\title{
Plasma Membrane-derived Vesicles (PMVs) in G6PD Deficient Patients
}

\author{
Samuel Antwi-Baffour*, Andrew Owusu Boafo, Ransford Kyeremeh and Seidu Abdulai \\ Mahmood \\ Department of Medical Laboratory Sciences, School of Allied Health Sciences, College of Health Sciences, University of Ghana, Korle-Bu, Accra
}

\begin{abstract}
Received: November 28, 2013; Accepted: December 23, 2013; Published: December 26, 2013
*Corresponding author: Samuel Antwi-Baffour, Department of Medical Laboratory Sciences, School of Allied Health Sciences, College of Health Sciences, University of Ghana, Accra, Tel: 233-0-268892613; Email: s.antwi-baffour@chs.edu.gh
\end{abstract}

\begin{abstract}
Background: Plasma membrane-derived vesicles (PMVs) are described as sub-cellular vesicles released upon shear stress, cell activation, injury or apoptosis. They are considered as universal biomarkers in a wide range of physiological and pathological processes. Glusoe-6-phosphate dehydrogenase (G6PD) deficiency on the other hand is an $\mathrm{x}$-linked enzymopathy characterized by the inability of red blood cells (RBCs) to withstand oxidative stress. The presence and role of PMVs in G6PD deficiency has not been fully investigated.
\end{abstract}

Objectives: The aim of this study was to quantify and compare the levels of PMVs in G6PD deficient and non-deficient patients.

Methods: G6PD deficiency test using the methaemoglobin reduction method was performed on the blood samples. The levels of PMVs in those samples were quantified using quantitative flow cytometry. This was done by centrifuging the blood samples to obtain platelet-free plasma. Annexin V was then added to label the PMVs and quantified by flow cytometry.

Results: The mean level of PMVs among G6PD full defects subjects was $26 \times 10^{4} \mathrm{PMVs} / \mathrm{ml}$ and that among the G6PD normal subjects was $10 \times 10^{4} \mathrm{PMVs} / \mathrm{ml}$. Statistically, the difference between the PMV levels of the G6PD normal samples and G6PD deficient samples was significant $(\mathrm{p}<0.05)$.

Conclusion: There is an increased level of PMVs in the circulating blood of G6PD deficient individuals as compared to G6PD normal individuals.

Keywords: G6PD, Plasma membrane; Deficiency; Apoptosis.

\section{Abbreviations}

ATP: Adenosine Triphosphate; EDTA: Ethylene Diamine Tetracetic Acid; FACS: Fluorescence Activated Cell Sorting; G6PD: Glucose-6-phosphate Dehydrogenase; NADP: Nicotinamide Adenine Dinucleotide Phosphate; NADPH: Reduced Nicotinamide Adenine Dinucleotide Phosphate; PBS: Phosphate Buffered Saline; PFP: Platelet Free Plasma; PMVs: Plasma Membrane- derived Vesicles; RBC: Red Blood Cells; SLE: Systemic Lupus Erythematosus

\section{Introduction}

Red blood cells (RBCs) require constant energy to maintain their biconcave disc shape and haemoglobin in reduced form [1]. Without adequate energy, RBCs will lyse and/or deform. RBCs gain energy in the form of adenosine triphosphate (ATP) from glucose which is derived from metabolism via anaerobic glycolysis (Embden-Myerhof pathway)[1,2]. There is also an alternate aerobic pathway (pentose-phosphate shunt) which starts with Glucose-6-Phosphate under the catalysis of Glucose-6phosphate dehydrogenase (G6PD) [2]. Low G6PD activity results in low levels of nicotinamide adenine diphosphate hydrogenase (NADPH) and reduced glutathione, which are required to protect hemoglobin from oxidative damage [3]. In the absence of adequate reducing ability provided by G6PD, oxidizing agents convert haemoglobin to methemoglobin, and then denature it, causing it to precipitate as Heinz bodies within the cell [3]. The spleen pinches off the Heinz body and the overlying membrane, leaving a "bite cell" or "blister cell" which eventually haemolysis.

G6PD deficiency is a X-chromosomally transmitted disorder of RBCs that affects 400 million people Worldwide. The deficiency is mainly found in malaria endemic areas and it has been suggested that it offers protection against malaria infection [4]. While the molecular biology of G6PD deficiency has been extensively studied, the molecular mechanisms leading to the haemolytic crisis are still unclear [5]. However, some membrane alterations have been described in G6PD deficient red blood cells, such as the oxidation and clustering of membrane proteins, the binding of hemichromes to the internal face of the membrane, the destabilization of the membrane and the release of microvesicles [6]. There is therefore the suspicion of increased levels of Plasma Membrane-derived Vesicles (PMVs) in G6PD deficient patients.

PMVs are membrane-coated vesicles of diameter 0.1 to 1 $\mu \mathrm{m}$. They are released when cells undergo activation/apoptosis via blebbing and shedding and have a function in intercellular communication. PMVs are released from the membranes of cells 
and therefore contain cell surface or membrane proteins and cytoplasmic components of their parent cells [7]. The presence of basal levels of PMVs is common in healthy individuals and an increase in their release although a controlled event, is a hallmark of cellular alteration [8]. Increased numbers of circulating PMVs have been identified in individuals with diseases such as hypertension, thrombotic thrombocytopenic purpura, systemic lupus erythematosus (SLE), multiple sclerosis, cerebral malaria and many others associated with inflammation [9]. G6PD deficiency disease is also associated with inflammation and hence the suspicion that PMVs levels may be high in those patients. Although the prognostic potential of circulating PMVs is still in its infancy, the different studies being carried out clearly demonstrate that their detection and quantification is an interesting and potentially valuable tool to appreciate in disease states and also may indicate the severity of that disease state [10].

\section{Materials And Methods}

This was a prospective study conducted from the month of May to June, 2013.

\section{Study population}

The study population was made up sixty six (66) patients who were suspected of G6PD deficiency and were requested to do the test. Out of the total number, 47 were males and 19 females. Their ages ranged from 5 to 40 years which were categorized into 5 10yrs; 11 - 20yrs; 21 - 30 yrs and 31 - 40yrs. Those who tested positive for G6PD full defect (33) became the study group and those who tested negative (33) for the defect were the control group.

\section{Ethical consideration}

Ethical clearance for this research was sought from the Ethics and Protocol Review Committee at the School of Allied Health Sciences, University of Ghana, Legon. All the participants gave their informed consent before their samples were collected. No G6PD partial defects were obtained.

\section{Materials}

Some of the materials needed for the work include: FACSFlow Cytometer, sonicating water-bath (Townson and Mercer Ltd, Croydon), Centrifuge - Eppendorf 5810R, Rotor number A-4-62, Micro-centrifuge - Eppendorf 5417R, Rotor number FA 45-24-11, Ethylene diamine tetracetic acid (EDTA) tubes, Pasteur pipettes, sodium nitrite $(0.7 \mathrm{~g} \%)$ and methylene blue $(10 \mathrm{mg} / \mathrm{ml})$ reagents and phosphate buffered saline (PBS- pH 7.2).

Sample collection and processing: $10 \mathrm{ml}$ of whole blood from each individual was collected into EDTA anticoagulant tubes. $5 \mathrm{ml}$ of the blood was used to perform a G6PD deficient test to know or confirm participant's G6PD status. The remaining 5 $\mathrm{ml}$ was spun at $2000 \mathrm{~g}$ for 10 minutes and the plasma separated for the quantification of the PMVs. For the G6PD screening the methaemoglobin reduction method as in Cheesbrough, 2010 was used.

With the flow cytometry analysis of PMVs, Frozen plasma was allowed to thaw, and centrifuged at a higher speed (4
$000 \mathrm{~g}, 60$ minutes) to obtain platelet free plasma (PFP) and to remove any cell debris. The resultant supernatant was sonicated in a sonicating water-bath for $5 \times 1$ minute prior to further centrifugation, in order to disperse aggregated exosomes. The supernatant was then centrifuged at $25000 \mathrm{~g}$ for 90 minutes to pellet the PMVs. The supernatant was discarded, and the pellets containing the PMVs resuspended in $200 \mu$ l phosphate buffered saline (PBS-pH 7.2). An aliquot of this was diluted in the ratio of 1:40 in PBS (pH 7.2). A $100 \mu \mathrm{l}$ of the diluted sample was put in a 96 well plate, equal volume of annexin $\mathrm{V}$ added and quantified using Guava Express plus (FACS- Flow Cytometer). Three (3) different measurements (technical repeats) were done for each patient.

Data analysis: Data from the study was analysed using the Statistical Package for Social Sciences (SPSS) version 20.0 and summary was presented as a descriptive statistics of mean. The student's t-test for unpaired data was used to compare the differences in PMVs levels between G6PD deficient and nondeficient samples. A p-value $<0.05$ was considered significant. Graph pad prism version 6.0 and Microsoft Excel 2007 was used to construct the graph and bar chart respectively.

\section{Results}

The study population was made up of 47 males and 19 females who were between the ages of 5 to 40 years. Out of this number, 27 of the males and 6 of the females showed G6PD full defect whilst 20 of the males and 13 of the females showed no defect (the control group). The age category of $21-30$ yrs showed the highest number of full defect followed by the 31 40yrs. Generally, 4 patients in age category $5-10 y r s$ were full defect as against 6 who were no defect, then 6 against 7 in age 11-20yrs; 13 against 11 in category 21 -30yrs and 10 against 9 in age category 31 - 40yrs (Table 1 ).

All the samples were analysed for their G6PD status. 50\% of the 66 samples obtained were G6PD full defect and 50\% No defect. No partial defects were obtained. There was clear difference between the levels of PMVs in the G6PD full defect patients as against the No defect ones (Figure 1). The table below (Table 2) shows the descriptive statistics of the PMV levels in the G6PD normal and full defect samples. The minimum, maximum and mean values of the full defect and no defect samples clearly emphasize the difference in PMVs levels of the two G6PD statuses.

The highest PMV level among the full defect subject was 32

\begin{tabular}{|c|c|c|c|c|c|}
\hline $\begin{array}{c}\text { Age categories } \\
\text { (yrs) }\end{array}$ & \multicolumn{2}{|c|}{ Males } & \multicolumn{2}{c|}{ Females } & Percentage \\
\hline & $\begin{array}{c}\text { Full } \\
\text { Defect }\end{array}$ & $\begin{array}{c}\text { No } \\
\text { Defect }\end{array}$ & $\begin{array}{c}\text { Full } \\
\text { Defect }\end{array}$ & $\begin{array}{c}\text { No } \\
\text { Defect }\end{array}$ & \\
\hline $5-10$ & 3 & 4 & 1 & 2 & $\mathbf{1 3 . 6}$ \\
\hline $11-20$ & 6 & 4 & 0 & 3 & $\mathbf{2 1 . 2}$ \\
\hline $21-30$ & 10 & 9 & 3 & 2 & $\mathbf{3 6 . 4}$ \\
\hline $31-40$ & 8 & 3 & 2 & 6 & $\mathbf{2 8 . 8}$ \\
\hline Total & $\mathbf{2 7}$ & $\mathbf{2 0}$ & $\mathbf{6}$ & $\mathbf{1 3}$ & $\mathbf{1 0 0}$ \\
\hline
\end{tabular}

Table 1: A table representing participants' age, sex and G6PD status. 
$\times 10^{4} \mathrm{PMVs} / \mathrm{ml}$ and the lowest was $22 \times 10^{4} \mathrm{PMVs} / \mathrm{ml}$ whilst in the normal the highest PMV level was $22 \times 10^{4} \mathrm{PMVs} / \mathrm{ml}$ and the lowest $7 \times 10^{4} \mathrm{PMVs} / \mathrm{ml}$. The mean level of PMVs among the full defects subjects was $26 \times 10^{4} \mathrm{PMVs} / \mathrm{ml}$ whilst the mean level among the normal subjects was $10 \times 10^{4} \mathrm{PMVs} / \mathrm{ml}$ (Figure 2).

\section{Discussion}

Plasma membrane-derived vesicles (PMVs) have been identified at basal levels (2 - $\left.10 \times 10^{4} \mathrm{PMVs} / \mathrm{ml}\right)$ in blood of normal individuals whilst in diseases such as hypertension,

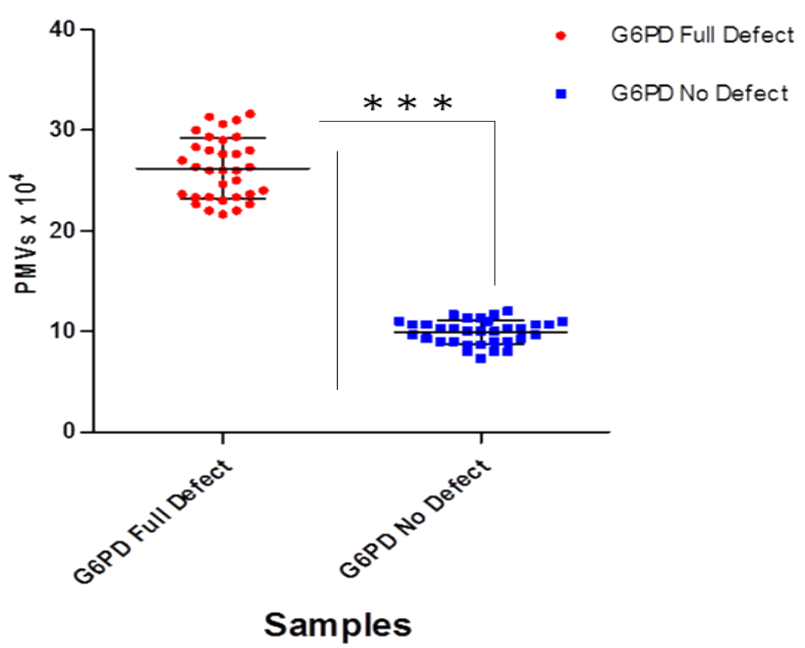

Figure 1: G6PG full defect plasma levels of PMVs are higher than those of G6PG No defect plasma.

\begin{tabular}{|l|c|c|c|c|c|c|}
\hline & $\begin{array}{c}\text { Num- } \\
\text { ber }\end{array}$ & $\begin{array}{c}\text { Mini- } \\
\text { mum } \\
\text { value }\end{array}$ & $\begin{array}{c}\text { Maxi- } \\
\text { mum } \\
\text { value }\end{array}$ & $\begin{array}{c}\text { Mean } \\
\text { value }\end{array}$ & $\begin{array}{c}\text { Std. } \\
\text { Error }\end{array}$ & $\begin{array}{c}\text { Std. } \\
\text { Deviation }\end{array}$ \\
\hline Full Defect & 33 & 22 & 32 & 26.20 & 0.528 & 3.033 \\
\hline No Defect & 33 & 7 & 12 & 9.93 & 0.209 & 1.198 \\
\hline $\begin{array}{l}\text { Valid N } \\
\text { (listwise) }\end{array}$ & 33 & & & & & \\
\hline
\end{tabular}

Table 2: Descriptive statistics of PMVs levels.

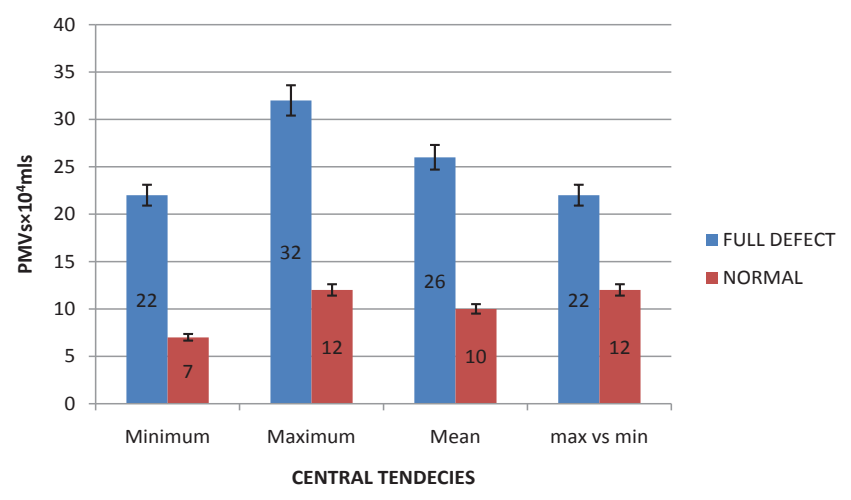

Figure 2: Shows the central tendencies of the PMV level of the G6PD full defect and normal samples. thrombotic thrombocytopenic purpura, multiple sclerosis, cerebral malaria and many others associated with inflammation the circulating PMV levels are increased $\left(10-30 \times 10^{4} \mathrm{PMVs} / \mathrm{ml}\right)$ $[9,10]$. In this study, there was a significant difference $(p<0.005)$ between the level of the PMVs in the full defect sample and the normal samples. Even the minimum level of PMVs recorded in the G6PD full defect sample $\left(22 \times 10^{4} \mathrm{PMVs} / \mathrm{ml}\right)$ was higher than the maximum level $\left(12 \times 10^{4} \mathrm{PMVs} / \mathrm{ml}\right)$ recorded in the G6PD normal samples. This clearly demonstrates that there are increased levels of circulating PMVs in the blood of the G6PD full defect individuals who participated in the study.

A study conducted by Pantaleo showed that the treatment of G6PD deficient red cells with diamide or divicine causes an increase in the oxidation and tyrosine phosphorylation of AE1. This leads to subsequent vesiculation of the red cells thus production of PMVs [11]. Diamide and divicine are compounds extracted from fava beans which can cause severe haemolytic crisis in G6PD deficient subjects [12]. In the study, Pantaleo identified and characterized the PMVs as likely to have been produced from G6PD deficient red blood cells by illustrating hemichromes in the PMVs produced [11].

The accumulation of hemichromes leads to the formation of Heinz Bodies which are additional hallmark of the haemolytic crisis in G6PD deficient individuals [11]. Based on Pantaleo's illustration, the higher levels of PMVs recorded in the G6PD full defect samples can be said to be as a result of increased activated red blood cells in the full defect subjects. This implies that the level of PMVs in a G6PD deficient individual can be used as a marker of the level of severity of erythrocyte stress and therefore crisis $[13,14]$. There were some limitations during the research work. These include not obtaining G6PD partial defect participants as well as low sample population.

\section{Conclusion}

There are increased levels of PMVs in the circulating blood of G6PD deficient individuals as compared to G6PD normal individuals. The increased PMVs levels may be attributed to the stress the G6PD deficient red blood cells may be going through.

\section{Acknowledgements}

We are grateful to the Central Laboratory of the Korle-Bu Teaching Hospital for providing us with the samples and the Haematology Laboratory of the School of Allied Health Sciences for their help in analysing them.

\section{References}

1. Beutler E, Duparc S (2007) Glucose-6-phosphate dehydrogenase deficiency and antimalarial drug development. The American journal of tropical medicine and hygiene 77: 779-789.

2. Bertil E, Glader A (2002) A review on genetics and Pathophysiology of Glucose-6-Phosphate Dehydrogenate deficiency. Blood 15: 150.

3. Baker MA, Bosia A, Pescarmona G, Turrini F, Arese P. (1984) Mechanism of action of divicine in a cell-free system and in glucose6-phosphate dehydrogenase-deficient red cells. Toxicologic pathology 12(4): 331-336. 
4. Tishkoff SA, Varkonyi R, Cahinhinan N, Abbes S, Argyropoulos G, et al. (2001) Haplotype diversity and linkage disequilibrium at human G6PD: recent origin of alleles that confer malarial resistance. Science 293: 455-462.

5. Beutler E. (2008). Glucose-6-phosphate dehydrogenase deficiency: a historical perspective. Blood 111: 16-24.

6. Caprari PP, Bozzi AA, Ferroni LL, Giuliani AA, La Chiusa BF BF et al. Membrane alterations in G6PD- and PK-deficient erythrocytes exposed to oxidizing agents. Biochemical medicine and metabolic biology 45: 16-27.

7. Bevers EM, Wiedmer T, Comfurius P, Zhao J, Smeets EF, et al. (1995) The complex of phosphatidylinositol 4,5-bisphosphate and calcium ions are not responsible for Ca2+-induced loss of phospholipid asymmetry in the human erythrocyte: a study in Scott syndrome, a disorder of calcium-induced phospholipid scrambling. Blood 86: 1983-1991.

8. Berckmans RJ, Nieuwland R, Boing AN, Romijn FP, Hack CE,et al. (2001) Cell-derived microparticles circulate in healthy humans and support low grade thrombin generation.Thromb Haemost 85: 639646.

9. Antwi-Baffour S, Kholia S, Aryee YK, Ansa-Addo EA, Stratton D, et al. (2010) Human Plasma Membrane-derived Vesicles inhibits the phagocytosis of apoptotic cells possible role in SLE. Biochem. Biophys Res Commun 398: 278-283.

10. Boulanger CM, Scoazec A, Ebrahimian T, Henry P, Mathieu E, et al. (2001) Circulating microparticles from patients with myocardial infarction cause endothelial dysfunction. Circulation 68: 87-89.

11. Pantaleo A, Ferru E, Carta F, Mannu F, Simula LF, et al. (2011) Irreversible AE1 Tyrosine Phosphorylation Leads to Membrane Vesiculation in G6PD Deficient Red Cells. PLoS ONE 6(1):15847

12. Chevion M, Navok T, Glaser G, Mager J. (1982) The chemistry of favisminducing compounds. The properties of isouramil and divicine and their reaction with glutathione. European journal of biochemistry/ FEBS 127: 405-409.

13. Ansa-Addo EA, Lange S, Stratton D, Antwi-Baffour S, Cestari I, et al. (2010) Human plasma membrane-derived vesicles halt proliferation and induce differentiation of THP-1 acute monocytic leukaemia cell. Jour. Immunol 185:5 236-5246.

14. Cheesbrough M (2010) District Laboratory Practice in Tropical Countries Part 2. (2ndedn), Cambridge: Tropical Health Technology and Cambridge University Press. 